\title{
COMPASSION FATIGUE IN STUDENT AFFAIRS PRACTITIONERS WORKING WITH UNDOCUMENTED COLLEGE STUDENTS
}

\author{
Zelideh R. Martinez Hoy \\ Bard College
}

David Hoa Khoa Nguyen

Indiana University - Purdue University Indianapolis (IUPUI)

Given the nature of student affairs work, practitioners may be exposed to work-related stress that impacts their professional and personal well-being. In this phenomenological study, we examined the lived experiences of 9 professionals who worked with undocumented students and how they experienced and managed their compassion fatigue. Findings indicate that the predisposition to advocate and support along with expectations were prevalent triggers to compassion stress. Implications for professionals, their supervisors and institutions are discussed. 
tudent affairs professionals that work with undocumented students are not well trained by their institutions to hold multiple roles when providing support to their students and families (Lynch, 2017a; Martinez Hoy \& Gilbert, 2011). They are often called upon by multiple stakeholders (i.e. colleagues, high school administrators, students, and families) to respond to questions about policies, procedures, and best practices when working with undocumented students while serving as safe havens for their students but are not have not been properly trained by their institutions nor prepared by their graduate preparation programs since the field does not require clinical supervision nor certification (Lynch, 2017a). As a result, they must balance administrative and policy enforcement roles with assistance and advocacy roles in an environment with limited resources.

Since student affairs practitioners are uniquely positioned to advocate for their undocumented students, they must also stay informed about law and policies that extend beyond their institution (Martinez Hoy \& Nguyen, 2019). The stress from balancing undocumented students' experiences of trauma and professional duties may affect professionals' work and personal well-being. Compassion fatigue is a result of "helping or wanting to help a traumatized person" (Figley, 2002). Therefore, in-depth interest with students' situations compounded with personal and professional demands may lead to inadequate self-care and increased emotional cost as a helping provider.

Currently, there is scant research examining the experience of secondary traumatic stress or compassion fatigue among practitioners (Anderson, Guido-Brito \& Morell, 2000; Lynch, 2017a; Raimondi, 2019). Studies addressing compassion fatigue have mainly focused on the fields of psychotherapy, nursing, and the judicial system (Figley, 2002; Osofsky, Putnam, \& Lederman, 2008; Sabo, 2006). Their experiences must be explored further to understand how they advocate for undocumented students while managing and maintaining self-care. The purpose of this study was to: 1.) explore the experiences of practitioners working with undocumented students, and 2.) understand strategies for self-care through a phenomenological study. The research questions that we asked were:

1) What are the experiences of student affairs practitioners that may manifest into compassion fatigue?

2) What are the professional and personal effects for practitioners working with undocumented students?

\section{Compassion Fatigue}

Practitioners may experience satisfaction from listening to and comforting their students when responding to student incidents, but there may also be secondary negative effects called compassion fatigue (Figley, 2002). Compassion fatigue is an event experienced by individuals who help others in distress (Figley, 1995). Subsequently, helpers may be traumatized while showing compassion and empathy, which includes various student affairs professionals (Bernstein Chernoff, 2016; Lynch, 2017b; Stoves, 2014). Compassion fatigue can also be described as secondary traumatic stress since the helper does not experience the trauma/traumatic event first hand; the secondary traumatic stress is experienced emotionally by caring for the student (Newell \& MacNeil, 2011). According to Figley's secondary traumatic stress theory, one can be susceptible to trauma without directly having experienced physical harm or threat; traumatization can occur from simply learning about the event (Figley, 1995). For practitioners, fatigue manifests from establishing a relationship with students, learning about students' exposure to and resulting challenges from trauma, and lacking professional training or support.

\section{Applying Figley's model to student affairs}

Understanding how Figley's Compas- 
sion Fatigue model applied to student affairs illuminates the unique factors that contribute to compassion fatigue. Below is a description of how select constructs may manifest in student affairs work. available resources and knowledge to provide students with the needed support. This philosophy of holistic student development requires professionals to have a relationship with students that must be more than just relaying information (ACPA/NASPA, 1997; Carpenter, 2003; Evans \& Reason, 2001).

\section{Figure 1: The Compassion Fatigue Process (Figley, 2002)}

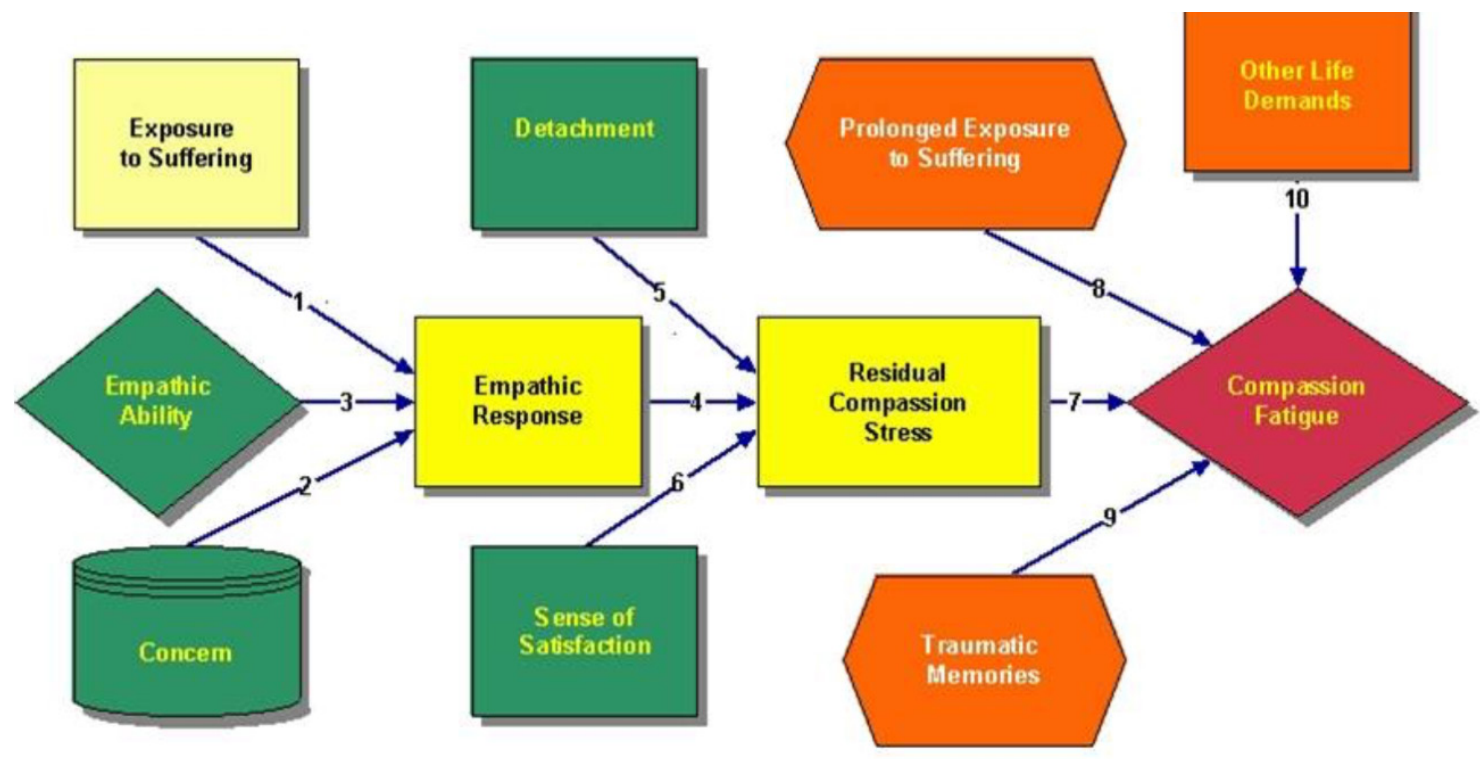

First, exposure to suffering is to bear the emotional energy from the distressed student through direct interaction (Figley, 1999). Since the field of student affairs plays a critical role in the development of college students, it is a professional requirement that professionals care about the growth of their students (American Council on Education, 1937; Boyer, 1987; Stoves, 2014). One reason a practitioner may leave direct practice of human services and shift into areas of supervision or administration is the cost of direct exposure to students' suffering through services provided to students (Figley, 1999; Maslach, 1982). Secondly, an individual must have empathetic concern or "the motivation to respond to people in need" (Figley, 2002). This means that practitioners also need the experience and motivation to support the student. Empathy to support the student is not enough to act but knowledge of resources is necessary to reinforce the willingness to help. With empathetic concern, practitioners will use
Third, practitioners must have empathetic ability or the capacity for the professional to observe the pain of the student (Figley, 1999). Without this there is limited if any stress while attempting to assist the student, which results in a limited response from the practitioner (Kinzie \& Schuh, 2008). Therefore, empathizing is at the core of helping the student and practitioners allowing themselves to be vulnerable to care. If all three above conditions are present, practitioners will exhibit an empathetic response that will mitigate student distress (Figley, 1999). It is key how practitioners project themselves into the emotions and behaviors of the student. The core of this response is the magnitude of positive impact the professional can have assisting the student with relevant support and resources while increasing the susceptibility and the potential emotional costs to the practitioner (Javinar, 2000; Kegan, 1982; Kuh et al, 1991). In the end, the practitioner can be rewarded for this empathetic response 
through students' academic or personal success, such as receiving an acceptance letter, scholarship, stable housing, or a job.

Compassion stress is the result from post empathetic response and is the lingering and continued poignant sentiment to alleviate the student from suffering or distress (Figley, 1999). This ongoing self-pressure along with day to day strains can greatly impact the personal health and performance of practitioners. Compassion stress can be impacted by either sense of achievement or disengagement. Sense of achievement is an element that either decreases or mitigates compassion stress (Figley, 1999). It allows for the experience of satisfaction from assisting their students. In addition to sense of achievement, a practitioner may experience disengagement, which also lowers or prevents compassion stress. This is the ability and extent to which practitioners can distance themselves from the students' situation post interaction or between interactions. This requires intentionality from the practitioner while recognizing the value of self-care and work-place structures for support.

An on-going sense of responsibility for a student can lead to prolonged exposure (Figley, 1999). For many, this takes the form of being an activist for their student (Kegan, 1982). Such involvement may lead them to other practitioners who are experiencing similar student situations, which can add stress to the prolonged exposure. This exposure can come with traumatic recollections, which are memories of students' experiences or stories that may generate post-traumatic stress disorder (PTSD) type symptoms (Figley, 2002). The most widely noted symptom in this study was the practitioners' inability to sleep or stay asleep thinking about students' issues and the impotence to do more for their students given the multilayered policies governing their lives.

\section{Symptoms \& Interventions}

Compassion fatigue emerged from studying the experiences of nurses, but its pervasiveness has developed in-depth literature on the prevailing symptoms for student affairs (Stoves, 2014). While studies of student affairs professionals have not focused on compassion fatigue, studies that examined issues of mental health or workplace stress among student affairs professionals also found similar symptoms. For example, Becker \& Drum (2015) explored issues of mental health among resident assistants (RAs) whom received suicidal prevention training. Their study found that RAs lacked both the training and the network to support their interventions with suicidal residents, which in turn exposed the RAs to negative mental health impacts. These experiences along with stressful duties added to adverse symptoms and outcomes (Morrison \& O'Connor, 2005). Stoves (2014) found that consequences of compassion fatigue in higher education can result in emotional exhaustion, detachment, and callousness, among others. Other symptoms can include forgetfulness, distancing themselves from others, inability to focus, issues of sleep, irritability, and avoidance (Lynch, 2019). The following table includes the most common physical and emotional indicators of compassion fatigue adapted from Lombardo \& Eyre (2011).

These symptoms rarely manifest exclusively and are experienced in tandem with other parts of the practitioner's professional and personal lives. Ongoing exposure to any one of these symptoms may eventually tax the practitioner to the point where the ability to do their job effectively may be compromised (Raimondi, 2019). Consequences to their professional lives may result in the practitioner's burnout and attrition from the profession (Marshall, Moore Gardner, Hughes \& Lowery, 2016; Raimondi, 2019). As a result, awareness of compassion fatigue and the symptoms is a first step to help explain, validate, and guide practitioners to create or request support. 
Table 1: Symptoms of Compassion Fatigue

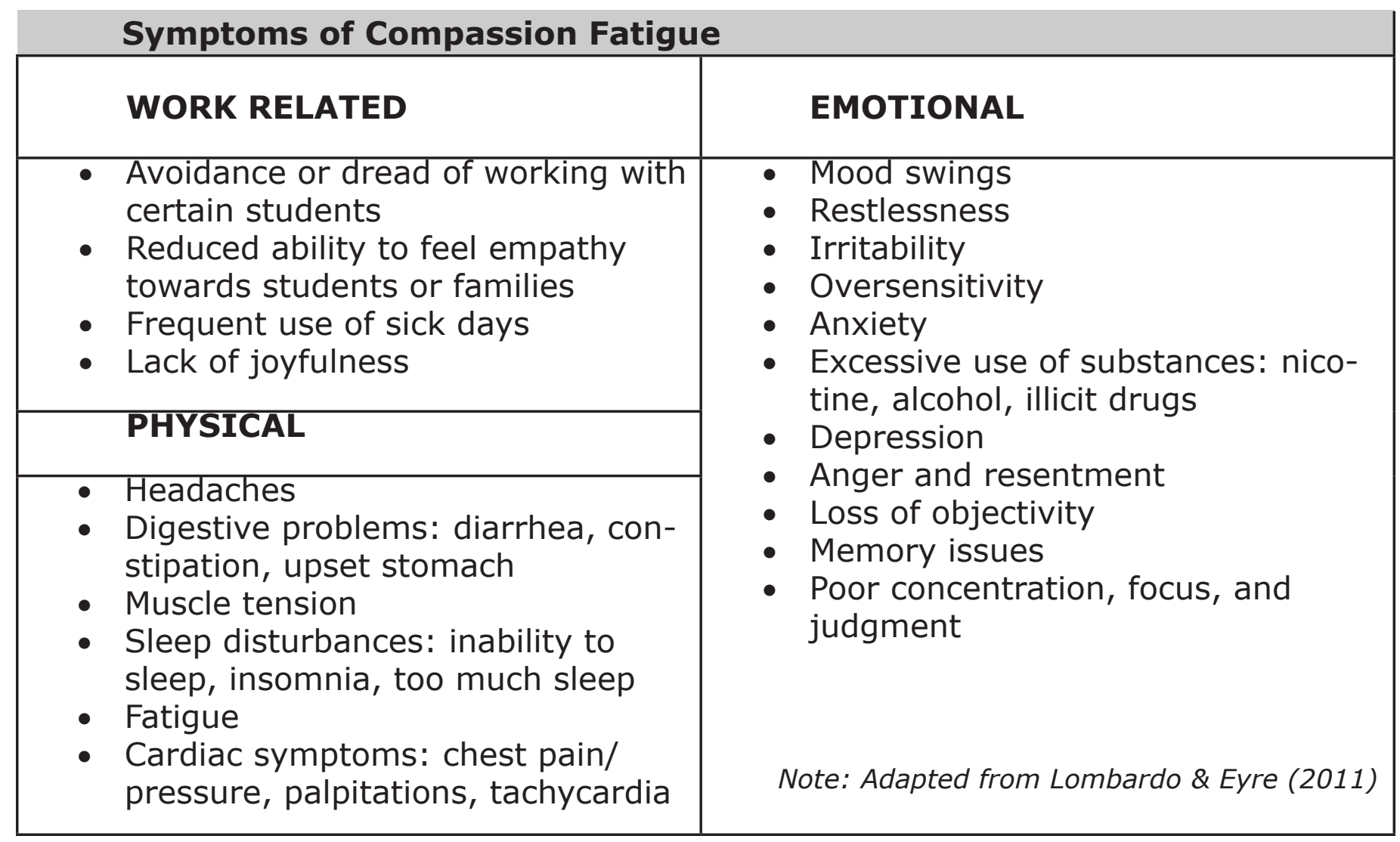

\section{Advocating for Undocumented Students}

Advocating for undocumented students can be very stressful given the maze of laws and policies a practitioner must navigate and the secondary trauma one experiences because of the anti-immigration sentiment and practices in society. While Plyler $v$. Doe afforded the right to a free public K-12 education to undocumented children since 1982 (Chapa, 2008; Lopez, 2005; Valencia, 2008), this equal educational opportunity does not extend to post-secondary education (Contreras, 2009). In 1986, Congress denied in-state resident tuition to undocumented students if the same were not afforded to U.S. nationals (Lopez, 2005). Since 2001 states have been passing their own DREAM Acts to afford in-state resident tuition to undocumented and DACAmented students, and a very select few have even afforded state financial aid (Serna, Cohen, $\&$ Nguyen, 2017). A few have made access even more difficult by banning enrollment, prohibiting in-state resident tuition, or not acting to provide state financial aid (Serna, Cohen, \& Nguyen, 2017; Nguyen \& Martinez Hoy, 2015; Nguyen \& Serna, 2014).

In 2012, Obama's Deferred Action for Childhood Arrivals (DACA) program began to give temporary reprieve to almost 1.9 million eligible undocumented youth enabling them to benefit certain rights without fear of removal proceedings (Batalova, Hooker, Capps, Bachmeier, \& Cox, 2013; Gonzales, Terriquez, \& Ruszczyk, 2014). While almost 2 million were eligible to receive DACA, only approximately 800,000 people received DACA as of fall 2017. Since DACA is only a temporary solution that grants "lawful presence" and does not grant "lawful status" or provide a pathway to legal permanent residency or citizenship, this presents a challenging barrier for undocumented youth to successfully integrate into the American society (Alba, Jimenez, \& Marrow, 2014; Kasinitz, Mollenkopf, Waters, \& Holdaway, 2008). Under the Trump Administration and 
the divisive political climate, DACA is even more uncertain since President Trump announced on September 5, 2017, that the DACA program would end. He called on Congress to act through legislative means, but immediately thereafter complaints were filed and courts have issued injunctions and ordered the federal Administration to continue providing protection under DACA without accepting additional applications. The status of DACA is still uncertain as the U.S. Supreme Court heard oral arguments in the fall 2019 and is expected to deliver a ruling by summer 2020 .

Undocumented students and their advocates must navigate and rely upon state legislation in order to access higher education or face state-directed barriers to college. Currently, twenty-one states acted either by legislation, board of regents' decisions, or state executive action to allow in-state resident tuition for undocumented or DACA students (Serna, Cohen, \& Nguyen, 2017). A number of states have legislated to color-blindly discriminate against undocumented students by shredding away their state residency and their college access. The interpretation and implementation of these policies depend on the efforts of practitioners that directly assist undocumented students navigate the bureaucracy of their institutions (Contreras, 2009; Martinez Hoy, 2014, Martinez Hoy \& Nguyen, 2019). While several studies examined the educational experiences of undocumented students (Abrego \& Gonzales, 2010; Contreras, 2009; Muñoz, 2015; Perez, Espinoza, Ramos, Coronado, \& Cortes, 2009), there is a dearth of studies that address the stressful experiences of the practitioners that service undocumented students to help them navigate these legal and policy barriers. This study attempts to bridge this gap by discussing the narratives of practitioners who have been working with undocumented students.

\section{Research Design}

Since many aspects of the student affairs practitioner's role and experience serving students cannot be divided into isolated variables, qualitative methods of inquiry were used to understand this complex phenomenon. The purpose of qualitative research is to understand and explain participant meaning (Merriam, 2009). Qualitative research is "an inquiry process of understanding based on distinct methodological traditions of inquiry that explore a social or human problem" (Creswell, 2012, p. 15). Researchers build a holistic picture, analyze words, report detailed observations of informants, and conduct the study in a natural setting (Creswell, 2012). Using a qualitative research design allowed the researchers to examine the lived experiences of student affairs practitioners working with undocumented college students.

\section{Interpretative Phenomenological Analysis}

We used interpretative phenomenological analysis (IPA) to analyze the interviews that included detailed narratives of practitioners' experiences, relationships, and emotions. Phenomenology allows researchers to delve into the core of the human experience as it is described by the participants living the phenomenon (Creswell, 2014). Its goal is to understand in-depth everyday experiences with its central focus being the lived experience of the world (Priest, 2002; Speziale, Streubert, \& Carpenter, 2011). Lived experiences are not open to a quantitative approach, so phenomenological methodology is utilized to capture and reveal how people experience the world in which they live (Jasper, 1994; Rapport \& Wainwright, 2006). Through individual face-to-face semi-structured interviews, we identified meaningful patterns or concerns through thematic analysis, which involved in-depth examination across interviews (Benner, 1994) and member checking with participants. IPA is distinct because of 
its combination of psychological, interpretative, and idiographic components. IPA has also been widely used in applied psychology, specifically in work relating to physical and mental well-being (Smith, 2004). IPA does not test a hypothesis or previous assumptions, but rather, the methodology aims to capture and explore the meaning that participants assign to their experiences (Smith \& Osborn, 2008). Participants are the experts of their lived experience and offer the researchers their personal perceptions of the situation instead of attempting to obtain an objective view of the experience (Reid, Flowers, \& Larkin, 2005). The methodology emphasizes the importance of language as interpretative and not solely descriptive (Giorgi, 1992). During the research process IPA was used to interpret the practitioners' perceptions about their experiences. Accordingly, the researchers worked with the participant in flexible collaboration to identify and interpret the relevant meanings that were used to make sense of the topic.

For each interview, responses were rephrased and short summaries were presented to each participant for member checking as a way to confirm the interpretation of information. The participants appreciated this as it served to further support their response or provide further perspective. This exchange allowed confirmation of initial interpretations for accuracy as a preliminary analysis. Then researchers' actively engaged in the processing of transcribed data by reading and re-reading the transcripts and becoming familiar with the content to code, outline, and note key phrases, summaries of content, and initial interpretations. Subsequent readings and annotations were completed to ensure sound identification of salient themes, and then emergent themes were listed in chronological order and concepts were grouped into superordinate themes (Smith \& Osborne, 2008). Superordinate themes were compared across cases to identify themes, which included phrases or concepts used by participants to illustrate their experience.
Sampling method, participant recruitment, \& data collection

Using a purposeful sampling method, participants were recruited if they were practitioners with current or previous service experience with undocumented students and were primary points of contact at their colleges and universities. All participants were recruited from an e-mail solicitation sent to members of a Midwestern state-wide non-profit organization of higher education practitioners who worked to enhance the Latinx educational experience in their state. From the email solicitation, nine professionally diverse practitioners volunteered to be a part of the study. Two identified as men and seven as women. These practitioners worked in a variety of areas that interacted with undocumented students, from community outreach, recruitment, retention, to advocacy of students at the higher education level, which included but were not limited to administrators, support staff, and student affairs personnel. The years of working experience varied from entry-level to very experienced. The uniqueness of the participants' lived experience brought forth a variety of lenses, which assisted in data triangulation. Each were from different institutions in their state.

\section{Limitations}

This framework was used loosely as a way of disclosing respondent's feelings, meanings, and understanding, while witnessing the process of compassion fatigue emerge. It is possible that the categorization of data reflects researchers' expectations, and thus research with a larger population of practitioners working with other populations should be considered. Similar to other studies examining a specific population within a very specific sector of the profession, there is danger with generalizing the experiences of a small number of people. These interviewed practitioners cannot represent the diversity of experiences of others working with undocumented students. It is important to note that these practitioners 
worked in a state with general anti-immigrant sentiment, and their experiences cannot be generalized to other states that may have more favorable laws and policies and stronger networks of professionals. Future studies should examine and represent the other areas in student affairs in various locales. These may include but are not limited to residential staff, sexual assault prevention and response workers, as well as those working with marginalized populations. that contributed to compassion stress and eventual fatigue. From the second research question, practitioners believed that in order to cope with the effects on their professional and personal lives, it was advantageous to embrace their advocate role and be aware of the accomplishments from their work.

\section{Predispositions to Caring}

According to Figley's (2002) Compassion Fatigue model, practitioners must have concern for students in order to produce an

\section{Table 2: Participant Demographics}

\begin{tabular}{|c|c|c|c|c|}
\hline Name & Gender & $\begin{array}{c}\text { Years } \\
\text { Working } \\
\text { in Higher } \\
\text { Education }\end{array}$ & $\begin{array}{c}\text { Type of } \\
\text { Institution }\end{array}$ & $\begin{array}{c}\text { Level of } \\
\text { Administration }\end{array}$ \\
Mary & Female & 6 & Private & Mid-level \\
\hline Lori & Female & 4 & Public & Entry \\
\hline Ernest & Male & 3 & Private & Entry \\
\hline Maya & Female & 4 & Public & Entry \\
\hline Karina & Female & 8 & $\begin{array}{c}\text { Community } \\
\text { Org. }\end{array}$ & Community Org. \\
\hline Lacey & Female & 10 & $\begin{array}{c}\text { Community } \\
\text { Org. }\end{array}$ & Community Org. \\
\hline Emily & Female & 15 & Public & Mid-level \\
\hline Tori & Female & 9 & Private & Mid-level \\
\hline Pablo & Male & 3 & Private & Entry \\
\hline
\end{tabular}

\section{Results}

The research questions from this study examined the experiences of student affairs professionals working with undocumented students that manifested into compassion fatigue and how compassion fatigue effected their professional and personal lives. From the first research question, (1) practitioners that worked with undocumented students had a predisposition to advocate and support, which many times yielded positive outcomes for students, but difficult cases were a detriment to the practitioner's well-being, and (2) professional, community, and personal expectations were prevalent triggers empathic response; participants described similar characteristics that increased their risk for compassion fatigue. Because they desired to advocate and support students and have an open-door policy that extended into their personal time, this desire led to felling burnt-out and juggling many balls, like outreach, recruitment and retention, and relationship building with families. The practitioners also recounted that their own predispositions to caring was supported by their partners and families. Mary, a mid-level student affairs practitioner, described the 12-hour days and weekends she worked early in her career, and it only worked because her partner was also balancing work 
and study. Even so, her partner believed she was trying to "take on the world" and save it, which she passionately defended by saying,

It's not just a job, it's a lifestyle; because relationships are tied to the heart, you can't leave them nine to five. You take it with you both in your heart and in your thinking process of "How do we help a family?"

While she developed trust and built connections with families, this meant she extended her working hours and met them in their homes; but after years, it took a toll on her family life. After transitioning to a new position with less one-on-one contact, she made peace with it:

And after five years or so, that's when I felt like I was running more of a sprint for those five years, as opposed to focusing on the marathon work. And so now I'm like, "OK, this is a marathon." And I have found if I'm not helping directly the families in that outreach component because other people are doing that, I have then taken it upon myself to educate those that are the policymakers.

Practitioners need to protect their students and their commitment to advocate on their behalf was fueled because practitioners identified with their students' experience as either a first-generation college student, from an immigrant family, or from a particular social economic background. Above all, the quality relationships established with students made way for emotional attachment and consequent empathy the practitioners felt.

Ericka and her family assisted one of her students when their parent was arrested,

At one point, I had those kids move in with us .... Just so that we could be called if anything were to happen at school and we could go to [parent/teacher] conferences and things like that to making sure they have gas money. It's been a variety of things that my husband and I have done.

Ericka's family, especially her husband, was very supportive of the dedication she had to her students. The sense of responsibility and care she had for them came from her belief that we all have a purpose to serve one another. She explained, "For me, it's faith. I don't think that we've been put on this Earth to do for just ourselves." She was aware of the strength of her conviction and its tolls on her health. While Ericka suffered a panic attack, this was not uncommon; all participants expressed some impact on their well-being by showing various symptoms of compassion fatigue noted earlier in the article.

\section{Expectations Became Triggers}

The participants were driven by their mission to help students through their activism, even if it required more time outside of their job duties compared to their colleagues. All felt a desire to lessen the burden on students by becoming more familiar with policy and the latest legal developments since it was a professional, personal, and community expectation. This ongoing response to understand and navigate the system became constant advocacy coalesced with the thoughts, emotions, and actions of their students; these became triggers to their symptoms of compassion fatigue.

As a recruiter, Lori felt inadequate to keep abreast with the ever-changing policies. She did not receive any training and keeping up with changes in policies and resources was emotionally draining because she had additional work compared to her coworkers without additional compensation. While her undocumented students were grateful for the support, she felt ill-equipped to assist them matriculate due to unknown institutional stances or inconsistent information due to the stigma surrounding undocumented immigration. It was hard for her not to be emotional as she added,

When it's an undocumented student in my office who has a 4.0, has done everything right, their goal has been to 
come to [X college], and they've been admitted to [X college], they think they're coming. I was suddenly informing them that they are an out-of-state student that they don't qualify for scholarships. I just am crushing them. That takes a toll on me. That is really hard, and I don't think I've cried in front of any students other than undocumented students. I sit there and I cry with them a lot of times because I just can't help it.

Repeated attempts to walk students through resources without tangible results made practitioners feel incompetent; students and families expected them to know the answers - they expected themselves to know the answers. Given the questioned legitimacy of the students' presence of campus, practitioners found themselves justifying their work. This justification questioned their vocation and doubted their relationship with students.

Participants vented with their counterparts at other institutions. Venting was especially helpful for those who did not have others to debrief with at their own school. They reported feeling understood without having to describe and contextualize every situation. These exchanges were meaningful to help manage the challenges experienced - therefore mitigated their compassion fatigue. Residual compassion stress is the remaining emotional energy from empathic responses and desire to relieve student suffering (Figley, 1999). For the participants, psychological suffering or student struggles was at the forefront of their own personal expectations to advocate. Several recounted a sense of survivor's guilt for their privilege of navigating higher education when their students experienced a multitude of barriers to access. Mary, a mid-level practitioner, felt strongly about going beyond her job description to be a resource and build a greater network with her students. This personal sense of responsibility was because she was a first-generation college student who figured out the college process herself.
Because of people that supported her, she felt that she was "paying it forward." Furthermore, she saw her role as a practitioner to break down barriers and help navigate students and their families.

These various expectations led to symptoms of compassion fatigue. Practitioners found themselves unable to sleep at night with recollections of students' stories and other anxieties about food insecurity, fear of deportation or detention a family member, and other life challenges. Implicitly, this heightened awareness and empathy is a result of accumulated and unresolved stress, which in this study, impacted the practitioners' sleep patterns, personal relationships, and at times dissatisfaction with their work. Ernest's home life was impacted by his job due to the amount of travel the job required including weekends. His partner believed that the compensation did not always match the time and energy spent or the stress incurred. Ernest also questioned the cost to the time spent with his child, but he quickly justified this with the greater role he served in his community. He stated,

Sometimes it can be stressful at home because it's like, "Man, you do so much for these kids. Are you going to be home in time for your son?" It's like I just have to make it work. It can be stressful because I can have a great day at the office and come home, and it's like, "Ugh, what happened?" I can have a great day at home and the office can just be hell. It goes both ways. In the end, I know that I'm here for a reason, and I have to keep reminding myself of that.

Since expectations of work-life balance impacted Ernest's home life, he and the other participants had to create a separation between their work and home. Figley (2002) defined detachment as the practitioner's professional ability to remove themselves from their client's distress and further argued that such distancing may mitigate the risk of compassion fatigue. However, because of the multi-layered challenges impacting practitioners, attachment or de- 
tachment is at the core of the practitioner's adaptive and maladaptive coping.

Stress from personal and professional expectations can be compounded with community expectations. All participants felt pressure to advocate for their students based on their professional ethos and personal commitments; but also they felt pressure either to support and educate their communities on these issues. Pablo saw his role as an educator, guide, and supporter while a recruiter for a private institution. He was in disbelief, shock, and frustration when he heard from high school counselors who told him which students to recruit or specifically forget because of their demographics and characteristics. He stressed,

There is a sense of privileged responsibility that is very much a part of what I try to implement on a daily basis in my professional and personal life. Because I've had the privilege to see and to travel to places where that is not a reality [for them], whether it be here in my hometown or whether it be hundreds and thousands of miles away in different countries.

The factors contributing to compassion fatigue were contextualized within complex environmental, professional, communal, and personal layers of demand on the practitioners. Their emotional labor was consistently unrecognized thus manifesting through their ways of coping.

\section{Embracing the Natural Advocate \& Being Aware}

Participants' self-identity was largely influenced by the understanding of their role beyond their job; they described it as more of their calling or vocation to serve others. Some participants spoke to this servitude with religious connotations, while others found it as a way of paying forward without regret. At the forefront, they exemplified the legacy most practitioners embrace by being advocates for students and their needs. Secondly, their calling was also to their family and community. Because some were first in their family to attend college or first to leave their immediate community, this added a lens of empathy to their advocacy. This awareness provided an understanding of their work and validated their commitment. Mary managed her symptoms through her faith, her church community, her relationship with God, and her family. When working with undocumented students and their families she recognized an incredible amount of resilience, which was an important for the job. Above all she learned that it was acceptable to take things personally and do them with love. She stated, "Don't be afraid to love. Don't be afraid to get involved. You're going to get hurt." Karina noted how her blind commitment to her students marked her professional life,

It gave me meaning and made me better. Even to this day, the reason I have the job that I have and the reason that in my professional life the things that I'm interested in and advocate for grew out of that learning that happened while working with my students. And while volunteering with them, it became what I wanted to do [for a career].

Her calling, like many others, was rooted in the profound connections established with her students. She saw them graduate high school, go to and pay for college, and struggle throughout. Karina managed her emotions by emotionally eating and venting her frustrations with other colleagues. She did not seek professional help, nor share her feelings with the students she worked with despite the space she created for them. As a figure of strength and a leader, she felt she needed to stay strong for her students and not show her vulnerability. She further emphasized that her feelings and issues were trivial compared to her students.

Sense of satisfaction can be a coping mechanism that can reduce or prevent residual compassion stress (Figley, 1999). While all participants questioned their role and ability to help students, which was magnified by various ongoing institutional 
and political changes, all highlighted a story that brought them fulfillment and a sense of hope in the job and presence at work. Uniquely, these stories all centered on student achievements, such as successful matriculation, financial sponsorship, or graduation. Every practitioner had a story they held on to as a symbol of optimism for their students' future and confirmation of their work. Several participants recognized the toll their work had on their personal lives and relationships and chose to move away from direct student service but remained in higher education. Their sense of obligation to the students transformed from direct service to creating awareness and professional development for others through conference presentations and support and mentoring of their colleagues. Karina emotionally accounted her experience by expressing her gratitude:

I owe so much to students organizing [around social justice issues] and to the students that I've worked with....when I said I've found myself, that's for real. That's what ignited my passion. I've always wanted to help people, but this has just become the thing I know. I just feel like I owe so much. Maybe that's where some of that guilt comes from. Like am I am not giving back enough.

Social justice movements on college campuses, such as Black Lives Matters, rallies for DREAMers, support for veterans, assistance for homeless students, etc., have a direct emotional impact on practitioners since they directly align with the social justice mission of the profession and the practitioners' predisposition to advocate for their students' academic and personal well-being. Raimondi (2019) reminded readers that while issues and concerns still persist for students, it is important to celebrate the small wins and focus on those needs that were met.

\section{Discussion and Implications}

Because the work of a student affairs practitioner is one of the pillars of the cam- pus structure (ACPA/NASPA, 1997), and the effects of compassion fatigue transcend the practitioner, implications should be considered at various levels. Based on the findings from this study, there are several strategies that would be helpful to professionals managing and reducing compassion fatigue: awareness of the condition and its symptoms, support from supervisors and leadership, and further training to build sustainability. Building awareness is the first step (Raimondi, 2019). Marc Brackett from the Yale Center for Emotional Intelligence is quoted, "If you can name it, you can tame it" (Simpson, 2017). Participants noted that awareness of compassion fatigue, its related symptoms, and implications can yield staff retention, job satisfaction, and delivery of empathic, quality student services. They would have been able to identify why they were getting panic attacks or not sleeping at night. They would have been able to understand how their working habits impacted their own health, well-being, and family life. Similarly to Mary, they would have understood that it was a marathon, and their work was for the long haul. Research found that a 5-week compassion fatigue resiliency education program for nurses helped 14 nurses become aware of their emotions and find overall work satisfaction 6 months later (Potter et al, 2013). As a result, once participants understood why they were exhibiting symptoms of compassion fatigue, they were able to figure out ways to manage it. Not only would understanding compassion fatigue and its consequences help individuals explain, validate, and begin to attain balance between their service and self-preservation, but it would also help supervisors and leaders know how this work impacts their employees personally and professionally.

Organizational culture and leadership are important to the response of maladaptive coping in compassion fatigue (Lynch, 2017a). Pearlman \& Saakvitne (1995) found that in order to respond appropriately to instances of compassion fatigue, treatment must address issues in three realms: 
personal, professional, and organizational. Literature has found that leadership and supervisors can play a role in reducing employee attrition in student affairs (Marshall et al, 2016). This also translates to helping professionals manage their compassion fatigue. Research has found that managers, leaders, and supervisors can mitigate the instances of compassion fatigue by implementing a number of interventions related to their employees' specific job duties (Slatten, Carson, \& Carson, 2011). Schmidt \& Haglund (2017) found that leadership can identify when nurses may be experiencing compassion fatigue and suggest interventions to help build resilience and reduce errors. In this study the participants noted they felt isolated in their workplace either because they had to do more work than their colleagues, deal with policy and political issues that their colleagues did not agree, or had to spend more time outside of working hours to address their student needs. All of these feelings triggered and added to their experience of compassion fatigue. If their supervisors understood compassion fatigue and its symptoms, they could implement several interventions to help their professionals manage their fatigue, such as reassignments of tasks, encouragement for time off or self-care, professional development, etc. While many times self-care is seen as individually-focused, support from supervisors and management can help its sustainability.

It is important that since student affairs professionals are helping professionals working directly with students that have trauma, they must be educated on compassion fatigue through graduate preparation programs and workplace professional development to reduce attrition rates. (Marshall et al, 2016). From the findings, it was not the challenge of advocating for students that impacted professionals' well-being but rather the depth of involvement. This level of involvement was explained as an issue of balance. While balance is essential for the longevity of the practitioner's ca- reer in student services, the contributing factors of gender, personal experience with the students' situation, and vocational commitment to the job, cannot be disregarded. Given the nuanced complexity of this condition, graduate preparation programs should inform, educate, and prepare future professionals about the potential of being susceptible (Koenig, Rodger, \& Specht, 2018; Reynolds \& Altabef, 2015). Employers and institutions should provide continuing professional development for current professionals to build awareness and strength to manage and mitigate compassion fatigue. It is important to understand the field and how the field can have an impact of new and mid-career professionals (Marshall et al, 2016). There are several instruments that faculty and leaders could use to help inform their students and employees about trauma-related conditions, such as the Professional Quality of Life scale (PROQoL) (Stamm, 2005), the Secondary Trauma in Resident Assistants Scale (STRAS) (Lynch, 2017b), the Secondary Trauma in Student Affairs Professionals Scale (STSAP) (Lynch \& Glass, 2019), or Haug's (2018) moral distress scale. Further, while acknowledgement of compassion fatigue alone does not shield practitioners from experiencing it, awareness can be a direct signal to the practitioner to intervene and manage the experience. This awareness can begin in professionals and their supervisors beginning in their graduate preparation programs and transfer into further professional development at their workplace. Management of compassion fatigue can look very different for different individuals; while some may enjoy a strenuous workout, others may benefit from quiet reading time. When one understands the concept of compassion fatigue, one is then able to be aware and find ways to reach compassion satisfaction.

Because practitioners bring unique experiences to the table, specifically those who are first-generation college students and/or have ethnic, cultural and multi-lingual abilities that enrich the working environment, 
institutions should value this visible and experiential diversity. However, the findings call for more awareness and proactive support from institutions, their departments, and supervisors. Social stigmas of various student issues were many times beyond the scope of practitioners' job duties but this did not keep students from trusting, confiding, and seeking advocacy. If institutions want to continue to enhance their communities and promote an inclusive and diverse campus environment, there must be a culture of care and support at every level, not just for students but also for the practitioners. To ignore the sustainability of student services staff is to ignore that of the students and the campus climate. Institutions and supervisory staff can recognize and understand how compassion fatigue manifests in their staff and find ways to manage large caseloads, provide time for self-care, and create a culture of support. Practitioners can then evidence the awareness and early efforts to support their advocacy work beyond their job responsibilities. Among the many benefits of reducing and mitigating compassion fatigue in any workforce are enhanced quality of work with students, increased work and decreased absenteeism, decreased turnover, and improved relationships (Marshall et al, 2016; Raimondi, 2019). Those experiencing compassion fatigue can experience symptoms, such as difficulty concentrating, loss of hope, exhaustion, becoming callous, and accepting more work; all factors affecting their personal and professional lives. Interventions to provide education and awareness of compassion fatigue, provide workplace structures to mitigate compassion fatigue, and institutionalize a culture of care can address various challenges in our profession.

\section{Conclusion}

Student affairs practitioners are helping professionals that are susceptible to vicarious or secondary trauma from their students. As a result, compassion fatigue can manifest in practitioners as a result of a combination of the environment, predisposition to advocate and support, and duress from professional, community, and personal expectations. It is crucial for our profession to evaluate and validate the support systems in place for practitioners who are closely intertwined in supporting and advocating for students. Since compassion fatigue has seldom been examined in the work of student affairs, our hope is that this will help create awareness among new and current practitioners of the cost of caring and inform institutions and their supervisors of this cost, especially among professionals that are working with a growing student population - undocumented students.

\section{References}

Abrego, L., \& Gonzales, R. (2010). Blocked paths, uncertain futures: The postsecondary education and labor market prospects of undocumented Latino youth. Journal of Education for Students Placed at Risk, 15(1-2), 144-157.

American College Personnel Association (ACPA) \& National Association of Student Personnel Administrators (NASPA) (1997). Principles of good practice for student affairs. Author. Retrieved from http://www. myacpa.org/pgd/principle.htm.

Alba, R., Jimenez, T. R., \& Marrow, H. B. (2014). Mexican Americans as a paradigm for contemporary intra-group heterogeneity. Ethnic and Racial Studies, 37(3), 446-466.

American Council on Education Studies (1937). The student personnel point of view. Author. Retrieved from http://www. myacpa.org/pub/documents/1937.

Anderson, J. E., Guido-DiBrito, F., \& Morrell, J. S. (2000). Factors that influence satisfaction for student affairs administrators. New Directions for Institutional Research, 2000(105), 99-110.

Batalova, J., Hooker, S., Capps, R., Bachmeier, J., \& Cox, E. (2013). Deferred Action for Childhood Arrivals at the one-year mark: A profile of currently eligible youth and applicants. Migration Policy Institute, 
8, 1-17.

Becker, M. A. S., \& Drum, D. J. (2015). The influence of suicide prevention gatekeeper training on resident assistants' mental health. Journal of Student Affairs Research \& Practice, 52(1), 76-88.

Benner, P. (1994). The tradition and skill of interpretive phenomenology in studying health, illness, and caring practices. Interpretive phenomenology: Embodiment, caring, and ethics in health and illness, 99-127.

Bernstein Chernoff, C. R. (2016). The crisis of caring: Compassion satisfaction and compassion fatigue among student conduct and behavior intervention professionals (Doctoral dissertation). Retrieved from ProQuest Dissertations \& Theses Global (1789879166).

Boyer, E. L. (1987). College: The undergraduate experience in America. Harper \& Row.

Carpenter, S. (2003). Professionalism. In Komives, S. R., \& Woodard Jr., D. B. (2003). Student services: A handbook for the profession. Wiley \& Sons.

Chapa, J. (2008). A demographic and sociological perspective on Plyler's children, 1980-2005. Northwestern Journal of Law and Social Policy, 3(2), 186-200.

Contreras, F. (2009). Sin Papeles y Rompiendo Barreras: Latino Students and the Challenges of Persisting in College. Harvard Educational Review, 79(4), 610-631.

Creswell, J. W. (2012). Qualitative inquiry and research design: Choosing among five approaches. SAGE Publications, Inc.

Creswell, J. W. (2014). Research design: Qualitative, quantitative, and mixed methods approaches (4th ed). SAGE Publications, Inc.

Evans, N. J., \& Reason, R. D. (2001). Guiding principles: A review and analysis of student affairs philosophical statements. Journal of College Student Development, 42(4), 359-377.

Figley, C. R. (1995). Compassion fatigue as secondary traumatic stress disorder: An overview. In C. R. Figley (Ed.), Compas- sion fatigue: Coping with secondary traumatic stress disorder in those who treat the traumatized (pp. 1-20). Brunner/Mazel.

Figley, C. R. (1999). Compassion fatigue: Toward a new understanding of the costs of caring. In B. H. Stamm (Ed.), Secondary traumatic stress: Self-care issues for clinicians, researchers, and educators (2nd ed., pp. 3-28). Sidran.

Figley, C. R. (2002). Compassion fatigue: Psychotherapists' chronic lack of self care. Journal of Clinical Psychology, 58(11), 1433-1441.

Giorgi, A. (1992). Description versus interpretation: Competing alternative strategies for qualitative research. Journal of Phenomenological Psychology, 23(2), 119-135.

Gonzales, R. G., Terriquez, V., \& Ruszcyk, S. P. (2014). Becoming DACAmented:

Assessing the Short-Term Benefits of Deferred Action for Childhood Arrivals (DACA). American Behavioral Scientist, 58(14), 1852-1872.

Haug, C. T. (2018). Identifying moral distress within student affairs administration in higher education: Its sources and lived experiences among student conduct administrators (Graduate thesis). Retrieved from University of Portland Pilot Scholars (42).

Jasper, M. A. (1994). Issues in phenomenology for researchers of nursing. Journal of Advanced Nursing, 19(2), 309-314.

Javinar, J. M. (2000). Student life and development. New Directions for Higher Education, 111, 85-93.

Kasinitz, P., Mollenkopf, J. H., Waters, M. C., \& Holdaway, J. (2008). Inheriting the city: The children of immigrant come of age. Harvard University Press.

Kegan, R. (1982). The evolving self: Problem and process in human development.

Harvard University Press.

Kinzie, J., \& Schuh, J. H. (2008). DEEP (Documenting Effective Educational Practice): Colleges and universities as communities. NASPA Journal, 45(3), 406-424. 
Koenig, A., Rodger, S., \& Specht, J. (2018). Educator burnout and compassion fatigue: A pilot study. Canadian Journal of School Psychology, 33(4), 259-278.

Kuh, G. D., Schuh, J. H., Whitt, E. J., \& Associates (1991). Involving colleges: Successful approaches to fostering student learning and development outside the classroom (Vol. 1). Jossey-Bass.

Lombardo, B., \& Eyre, C. (2011). Compassion fatigue: A nurse's primer. OJIN: The Online Journal of Issues in Nursing, 16(1), 3.

Lopez, M. P. (2005) Reflections on educating Latino and Latina undocumented children: Beyond Plyer v. Doe. Seton Hall Law Review, 35, 1373-1385.

Lynch, R. J. (2017a). Breaking the silence: A phenomenological exploration of secondary traumatic stress in US College student affairs professionals (Doctoral dissertation). Retrieved from Old Dominion University Digital Commons: https:// digitalcommons.odu.edu/efl_etds/43.

Lynch, R. J. (2017b). The development and validation of the Secondary Trauma in residents Assistants Scale. Journal of College and University Student Housing, 44(1), 10-29.

Lynch, J. R., \& Glass, C. R. (2019). The development of the Secondary Trauma in Student Affairs Professionals (STSAP) scale. Journal of Student Affairs Research and Practice, 56(1), 1-18.

Maslach, C. (1982). Burnout: The cost of caring. Prentice Hall.

Marshall, S. M., Moore Gardner, M., Hughes, C., \& Lowery, U. (2016). Attrition from student affairs: Perspectives from those who exited the profession. Journal of Student Affairs Research \& Practice, 53(2), 146-159.

Martinez Hoy, Z. R. (2014). The lived experience of higher education service

providers working with undocumented students: A phenomenological inquiry (Doctoral dissertation). Retrieved from ProQuest Dissertations and Theses (Accession Order No. 13301).
Martinez Hoy, Z. R., \& Gilbert, K., (2011). $A$ narrative inquiry into the experiences of higher education service providers working with undocumented Latino young adults. Unpublished paper.

Martinez Hoy, Z. R., \& Nguyen, D. H. K. (2019). Higher education professionals navigating anti-immigration policy for undocumented students. Educational Policy. https://doi. org/10.1177/0895904819857823.

Merriam, S. B. (2009). Qualitative research: A guide to design and implementation. Jossey-Bass.

Morrison, R., \& O'Connor, R. C. (2005). Predicting psychological distress in college students: The role of rumination and stress. Journal of Clinical Psychology, 61(4), 447-460.

Muñoz, S. M. (2015). Identity, social activism, and the pursuit of higher education: The iourney stories of undocumented and unafraid community activists. Peter Lang. Newell, J. M., \& MacNeil, G. A. (2011). A comparative analysis of burnout and professional quality of life in clinical mental health providers and health care administrators. Journal of Workplace Behavioral Health, 26(1), 25-43.

Nguyen, D. H. K., \& Martinez Hoy, Z. R. (2015). "Jim Crowing" Plyler v. Doe: The resegregation of undocumented students in American higher education through discriminatory state tuition and fee legislation. Cleveland State Law Review, 63(2), $355-371$.

Nguyen, D. H. K., \& Serna, G. R. (2014). Access or barrier? Tuition and fee legislation for undocumented students across the states. The Clearing House: A Journal of Educational Strategies, Issues, and Ideas, 87(3), 124-129.

Osofsky, J. D., Putnam, F. W., \& Lederman, J. C. S. (2008). How to maintain emotional health when working with trauma. Juvenile and Family Court Journal, 59(4), 91-102.

Pearlman, L. A., \& Saakvitne, K. W. (1995). Treating therapists with vicarious traumatization and secondary traumatic stress 
disorders. In C. R. Figley (Ed.), Compassion fatigue: Coping with secondary traumatic stress disorder in those who treat the traumatized (pp. 150-177). Brunner-Routledge.

Perez, W., Espinoza, R., Ramos, K., Coronado, H., \& Cortes, R. (2009). Academic resilience among undocumented Latino students. Hispanic Journal of Behavioral Sciences, 31(2), 149-181.

Plyler v. Doe, 457 U.S. 202 (1982).

Potter, P., Deshields, T., Berger, J. A., Clarke, M., Olsen, S., \& Chen, L. (2013). Evaluation of a compassion fatigue resiliency program for oncology nurses. Oncology Nursing Forum, 40(2), 180-187.

Priest, H. (2002). An approach to the phenomenological analysis of data. Nurse Researcher, 10(2), 50-63.

Raimondi, T. R. (2019). Compassion fatigue in higher education: Lessons from other helping fields. Change: The Magazine of Higher Learning, 51(3), 52-58.

Rapport, F., \& Wainwright, P. (2006). Phenomenology as a paradigm of movement. Nursing Inquiry, 13(3), 228-236.

Reid, K., Flowers, P., \& Larkin, M. (2005). Exploring lived experience. Psychologist, 18(1), 20-23.

Reynolds, A. L., \& Altabef, D. (2015). Addressing helping competencies in student affairs: Analysis of helping skills course syllabi. Journal of Student Affairs Research \& Practice, 52(2), 220-231.

Sabo, B. (2006). Compassion fatigue and nursing work: can we accurately capture the consequences of caring work? International Journal of Nursing Practice, 12(3), 136-142.

Schmidt, M., \& Haglund, K. (2017). Debrief in emergency departments to improve compassion fatigue and promote resiliency. Journal of Trauma Nursing, 24(5), 317-322.

Serna, G. R., Cohen, J. M., \& Nguyen, D. H. K. (2017). State and institutional policies on in-state resident tuition and financial aid for undocumented students: Examining constraints and opportunities. Ed- ucation Policy Analysis Archives, 25, 18. doi:10.14507/epaa.25.2809.

Simpson, A. (2017). Connection. In The innovation-friendly organization ( $p p$. 149178). Palgrave Macmillan.

Slatten, L. A., Carson, K. D., \& Carson, P. P. (2011). Compassion fatigue: What managers should know. The Health Care Manager, 30(4), 325-333.

Smith, J. A. (2004). Reflecting on the development of interpretative phenomenological analysis and its contribution to qualitative research in psychology. Qualitative Research in Psychology, 1(1), 39-54.

Smith, J.A. \& Osborn, M. (2008). Interpretative phenomenological analysis. In J.A. Smith (Ed.), Qualitative psychology: $A$ practical guide to research methods (2nd Ed., p. 51-80). SAGE Publications, Inc.

Speziale, H. S., Streubert, H. J., \& Carpenter, D. R. (2011). Qualitative research in nursing: Advancing the humanistic imperative. Lippincott Williams and Wilkins.

Stamm, B. H. (2005). The ProQOL manual:

The professional quality of life scale: Compassion satisfaction, burnout \& compassion fatigue/secondary trauma scales. Sidran.

Stoves, D. (2014). Compelled to act: The negotiation of compassion fatigue among student affairs professionals (Doctoral dissertation). Retrieved from ProQuest Dissertations and Theses Global (3620005).

Valencia, R. R. (2008). Chicano students and the courts. New York University Press. 